\title{
ESTUDO SOBRE ILUMINAÇÃO DE AMBIENTES DE TRABALHO: SALA DE DESENHO TÉCNICO DO CENTRO MULTIDISCIPLINAR DE PAU DOS FERROS- UFERSA
}

\author{
SILVA, Wiriany Kátia Ferreira (1); \\ SOUSA, Liz Gabrielle Barbosa (2); \\ NUNES, Eduardo Raimundo Dias (3); \\ RODRIGUES, Clara Ovídio de Medeiros (4)
}

(1) Universidade Federal Rural do Semi-Árido, Graduanda em Arquitetura e Urbanismo e-mail:wirianykatia16@gmail.com

(2) Universidade Federal do Semi-Árido, Graduanda em Arquitetura e Urbanismo e-mail:lizgabriellebs@hotmail.com

(3) Universidade Federal Rural do Semi-Árido, Doutor em Ciências e Engenharia de Materiais

e-mail: eduardo.dias@ufersa.edu.br

(4) Universidade Federal Rural do Semi-Árido, Mestre em Arquitetura e Urbanismo e-mail: clara.ovidio@ufersa.edu.br

\begin{abstract}
RESUMO
A ergonomia é o estudo que visa melhorar o bem-estar do ser humano ao realizar atividades cotidianas, uma vez que o local onde o indivíduo está inserido reflete diretamente na sua sensação de bem-estar. Segundo a Norma Regulamentadora 17, do Ministério do Trabalho e Emprego, em todos os locais de trabalho devem haver iluminação adequada a atividade exercida, sendo assim, é nesse viés que tal pesquisa se desempenha, analisando o índice de iluminância na sala de desenho técnico na Universidade Federal Rural do Semi-Árido, na cidade de Pau dos Ferros, no estado do Rio Grande do Norte.
\end{abstract}

Palavras chave: Ergonomia; Conforto Ambiental; lluminação.

\begin{abstract}
Ergonomics is the study that aims to improve the well-being of the human being while performing daily activities, since the place where the individual is inserted reflects directly on their sense of well-being. According to Norma Regulamentadora 17 of the Ministry of Labor and Employment, in all workplaces there should be adequate lighting for the activity carried out, so that, in this bias, such research is performed by analyzing the illuminance index in the technical drawing room at the University Federal Rural Semi-Arid, in the city of Pau dos Ferros, in the state of Rio Grande do Norte.
\end{abstract}

Keywords: Ergonomics; Environmental comfort; Illumination. 


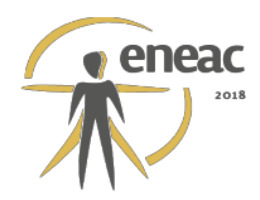

\section{INTRODUÇÃO}

O homem sempre busca adaptar, aprimorar e melhorar o seu bem-estar quando está exercendo atividades. No entanto, o conceito de ergonomia foi utilizado pela primeira vez em 1857, por Wojciech Jastrzebowski, biólogo polonês, no artigo "Ensaios de ergonomia ou ciência do trabalho, baseada nas leis objetivas da ciência sobre a natureza". No final do século XVIII, o trabalho era bastante desgastante, devido a busca intensiva da indústria europeia e americana para elevar a produção. Objetivava-se otimizar a mão de obra, assim, surgiram alguns métodos, e o que mais se destacou nessa época foi o Taylorismo. $O$ método, proposto por Frederick Winslow Taylor em meados do século XIX, em sua concepção, no trabalho, sem desvios ou adaptações, os exercícios repetidos melhorariam a produtividade. Junto a isso, a linha de montagem proposta por Henry Ford intensificou ainda mais a forma de trabalho dos cidadãos. Durante a Segunda Guerra Mundial, o conceito de ergonomia ressurge e começa a ser realmente aplicado, uma vez que perceberam que os armamentos precisavam ser adaptados ao porte dos militares, pois, ocorreram inúmeras falhas com aviões e dispositivos como radares, causados pela inadequação dos mecanismos às capacidades humanas, pois os equipamentos eram projetados para atingir metas de eficiência e funcionamento, mas não eram levadas em consideração as características psicológicas e fisiológicas do operador.

A ergonomia abrange diversas áreas, como a antropometria, a iluminação, o ruído, a temperatura, a velocidade do ar e a umidade relativa do ar, e sua aplicação no local de trabalho onde o indivíduo está inserido é de extrema importância para o bom funcionamento do ambiente, e da interação do ser humano-local, tanto para o bem-estar dos seus usuários, quanto para o rendimento da atividade exercida, o que estão diretamente relacionados. Segundo Itiro lida (2005), "a má iluminação aumenta a fadiga visual", e está interligada ao cansaço visual, dores de cabeça e insônia. Assim, pode-se constatar que ao tratar do desenvolvimento de tarefas visuais em ambientes construídos, um dos fatores que influencia diretamente é a iluminação.

O conforto visual apresenta um conjunto de condições que possibilitam a realização de atividades visuais com precisão, acuidade, menor risco de acidentes e esforços da visão, segundo Lamberts, Dutra e Pereira (2012). Dessa forma, a fim de definir os requisitos necessários para a obtenção e verificação do conforto visual de ambientes internos e externos, baseados na European Commission Directorate (1994), os mesmos autores citam que é necessária uma iluminação suficiente, com boa distribuição de iluminância, apresentando ausência de ofuscamento, além de, contrastes adequados e um bom padrão e direção de sombras.

A ausência do conforto visual pode facilitar a ocorrência de acidentes no trabalho, que prejudicam a saúde do trabalhador, como também, está diretamente ligado ao desempenho das atividades do ser humano. Nessa perspectiva, pode-se relacionar a iluminação adequada à dimensão funcional da tríade vitruviana, estudada por Lamberts, Dutra e Pereira (2012), a qual retrata sobre o equilíbrio entre as dimensões estruturais, formais e funcionais de um edifício, tendo assim, o conforto visual como imprescindível para esse equilíbrio.

Além disso, vale ressaltar que as condições ambientais intervêm na percepção do usuário em relação ao ambiente, deste modo, a luz é imprescindível no processo de interpretar corretamente o meio e suprir sem esforço a demanda das atividades recorrentes ao espaço. Assim, em detrimento dos ambientes de ensino, segundo Bertolotti (2007): "A luz é parte integrante do processo de aprendizagem escolar", uma vez que, como as salas de aula são locais do desenvolvimento de atividades que necessitam de muita atenção, para um bom desempenho visual, a iluminação é um fator preponderante que pode otimizar ou dificultar o ensino e aprendizado. Isso pode ser corroborado através da seguinte citação: "Quanto melhores as condições de iluminação, mais fácil e mais rápida a tarefa será realizada e 


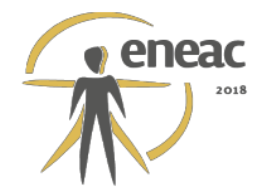

menor será o esforço para os olhos" (RENNHACKKAMP, 1964, p.1, apud BERTOLOTTI, 2007, p.19).

Outrossim, ao realizar a análise de um edifício é fundamental ter o conhecimento sobre quais os tipos de iluminação atuantes, seja natural, artificial ou ambas. Contudo, se essas forem utilizadas em um ambiente em níveis inadequados, podem causar, dores de cabeça, fadiga, estresse, assim como, irritabilidade nos olhos. Esses níveis vão variar de acordo com o tipo de atividades desenvolvidas ou perfil de usuário.

Dentre os aspectos para se assegurar o conforto visual, está o nível de iluminância mínima na área de trabalho, para que ocorra o desempenho da atividade com o mínimo esforço.

Com isso, a Norma Regulamentadora 17, segundo o Ministério do Trabalho e Emprego e a Secretaria de Inspeção do Trabalho (2002), determina a importância da relação entre conforto e espaço, visando estabelecer parâmetros, a fim de permitir melhores condições de trabalho, para proporcionar uma maior segurança e desempenho eficiente. Nessa mesma norma, o anexo 17.5 faz referência às condições ambientais de trabalho, que devem estar apropriadas às características psicológicas dos trabalhadores e ao gênero de trabalho. Assim, a aplicação dessa norma regulamentadora é de suma importância, tendo em vista que o espaço físico pode facilitar ou prejudicar a execução do trabalho.

Portanto, o objetivo da pesquisa consiste em comparar o índice de iluminância nos três períodos do dia, considerando a luz natural e artificial, analisados em cada prancheta presente na sala de desenho técnico da Universidade Federal Rural do Semi-Árido, Campus Pau dos Ferros, localizada no bloco de salas de aulas B, com os valores propostos na NBR 8995, a norma brasileira regulamentadora que estabelece parâmetros ergonômicos que a iluminação do interior de ambientes trabalho devem seguir para propiciar um boa iluminação ao ambiente.

\section{METODOLOGIA}

O percurso metodológico baseou-se na pesquisa de campo para a averiguação do ambiente, mediante a utilização do luxímetro, além de aplicar um questionário aos usuários do ambiente estudado, visando entender a influência do índice de iluminância ao realizar atividades. O estudo foi executado em todas as pranchetas da sala de desenho técnico, com iluminação natural e iluminação artificial. Segue abaixo a planta baixa da sala analisada.

Imagem 01- Planta baixa da sala de desenho técnico.

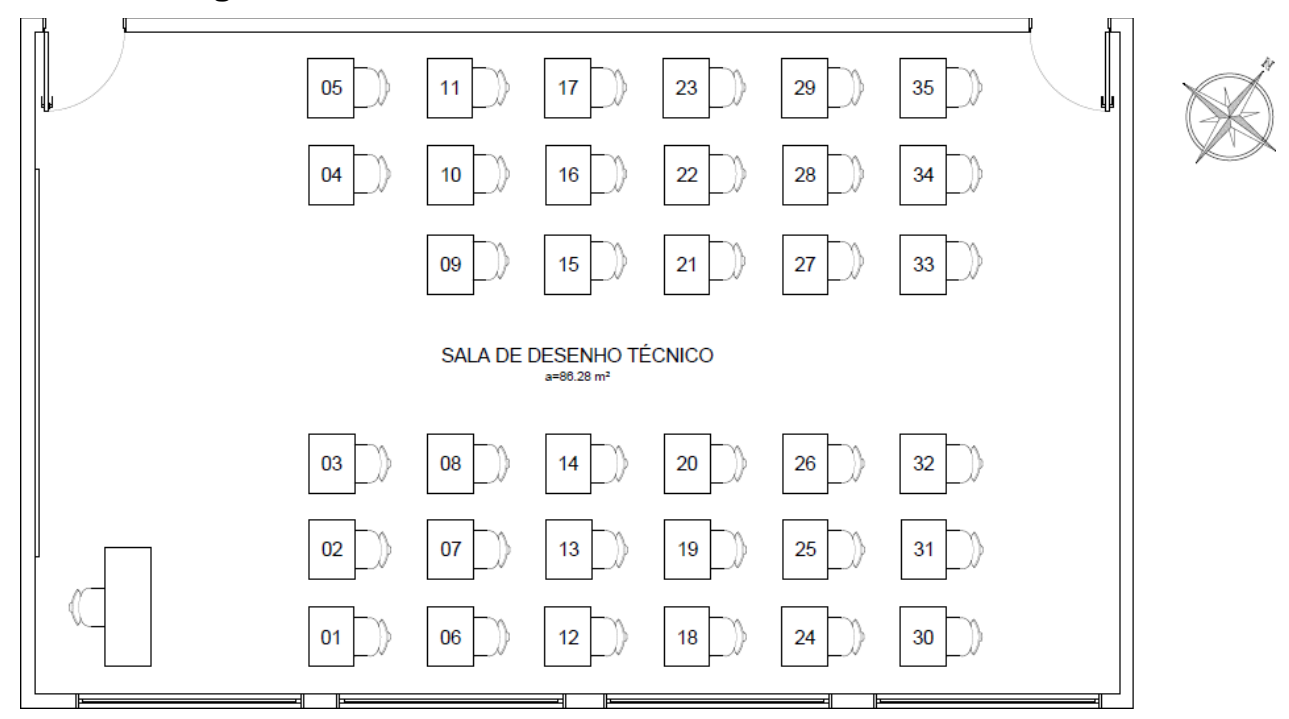




\section{(x) $^{\text {remax }}$}

Fonte: Autores (2018).

A pesquisa iniciou-se pela visita à sala do estudo, onde ocorreu a medição da iluminância de trinta e cinco cadeiras de desenhos distribuídas pela sala, durante o período da manhã, tarde e noite. Entretanto, nos períodos da manhã e da tarde realizou-se a averiguação em duas condições, com as janelas fechadas e abertas, contando com a iluminação natural e artificial em ambas. Optamos por fazer essas duas análises, pois os discentes e docentes que a utilizaram no período 2017.1, passaram por esses dois cenários (janela fechada com película e aberta sem película), uma vez que foram colocadas películas para evitar a elevada iluminância na área de trabalho. Após coletar os dados, comparamos com os valores mínimos de iluminância nas áreas de trabalho recomendados na NBR 8995, na Seção 5.

Não obstante, para corroborar as afirmações presentes nessa norma, utilizamos o mecanismo de Avaliação Pós Ocupação (APO), um processo de análise de edifícios já construídos, que tem como objetivo o estudo das pessoas que fazem a utilização dele, com o objetivo de buscar melhorias para projetos futuros, segundo Nakamura (2013). Logo, essa ferramenta possibilita a apresentação de propostas com soluções estruturais, para que o edifício apresente uma maior eficiência energética e, por conseguinte, conforto aos seus usuários.

Utilizamos Avaliação Pós-Ocupacional (APO), ao aplicarmos um questionário voltados para os estudantes de Arquitetura e Urbanismo, Ciência da Tecnologia e aos professores, com uma faixa etária de 18 a 40 anos de idade, que fazem o uso diário do ambiente estudado, após a aplicação das películas nas janelas, para assim, verificar a influência e percepção do usuário a acerca do ambiente. Segue abaixo o questionário utilizado.

Tabela 01- Questionário aplicado aos usuários da sala de desenho da UFERSA.

\begin{tabular}{|l|l|l|}
\hline & \multicolumn{1}{|c|}{ Perguntas } & \multicolumn{1}{|c|}{ Alternativas } \\
\hline 01 & $\begin{array}{l}\text { Você utiliza, em média, a sala de desenho durante } \\
\text { quantas horas por semana? }\end{array}$ & $\begin{array}{l}\text { Entre 1 e 3 horas ( ) } \\
\text { Entre 4 e 8 horas ( ) } \\
\text { Entre 9 e 12 horas ( ) } \\
\text { Mais que 12 horas ( ) }\end{array}$ \\
\hline 02 & $\begin{array}{l}\text { Você sente um desconforto na visão enquanto } \\
\text { está desenhando? }\end{array}$ & $\begin{array}{l}\text { Não ( }) \\
\text { Sim ( ) }\end{array}$ \\
\hline 03 & $\begin{array}{l}\text { O que você sente? } \\
\text { Não sinto nada ( ) } \\
\text { Outro: }\end{array}$ \\
\hline \multirow{2}{*}{04} & $\begin{array}{l}\text { Se sim, você acredita que tal desconforto se dá } \\
\text { pelo: }\end{array}$ & $\begin{array}{l}\text { Excesso de luz no ambiente ( ) } \\
\text { Falta de luz no ambiente ( } \\
\text { Não sinto desconforto ( ) } \\
\text { Outro: }\end{array}$ \\
\hline
\end{tabular}




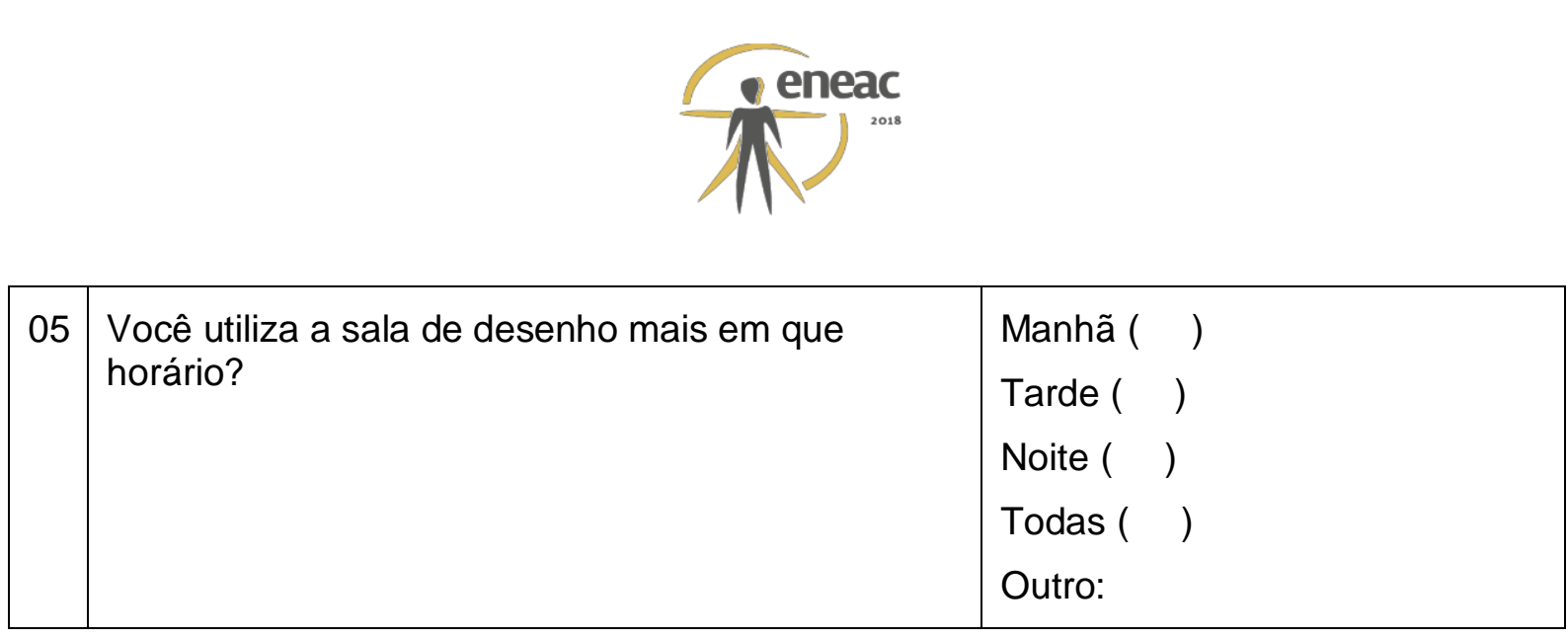

Fonte: Autores (2018).

Ademais, utilizamos o referencial bibliográfico, incluindo livros e artigos, a fim de entender um pouco mais sobre o assunto, para dominá-lo e, com isso, poder comparar e estudar as normas regulamentadoras que falam a respeito da ergonomia e do índice mínimo de iluminância em áreas de trabalho.

\section{RESULTADOS}

As medições foram realizadas com o uso do luxímetro nas trinta e cinco pranchetas, nos três turnos, sendo o da manhã medido em torno de 07:40 do dia 6 de fevereiro de 2018, os turnos da tarde e da noite foram medidos no dia 07 de fevereiro, sendo pela tarde às 15:45 e pela noite às 21:40. Não realizamos todas as medições no mesmo dia, pois optamos por fazer as medições em dias ensolarados, uma vez que a incidência dos raios solares na cidade do campo de estudo é predominantemente forte límpida, isto é, sem tantas nuvens.

\section{Imagem 02- Vista das janelas e luminárias do ambiente.}

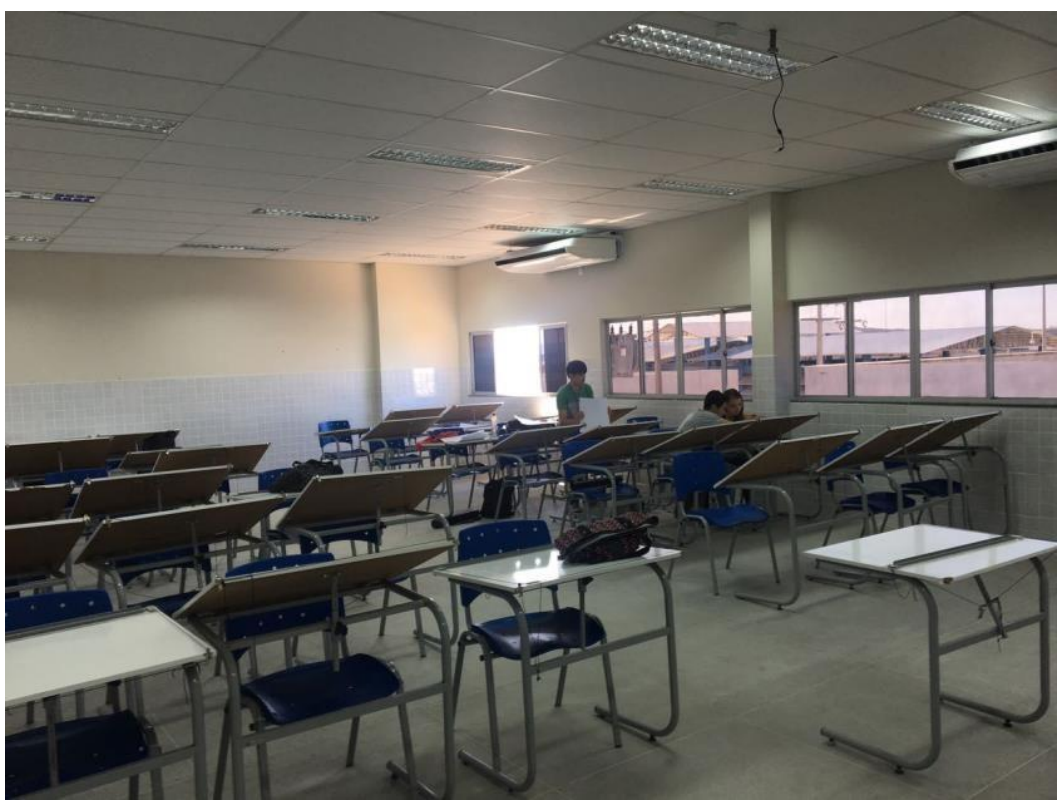

Fonte: Autores (2018).

Feitos os procedimentos supramencionados, analisamos e fizemos as medições com o luxímetro nos três turnos. Com isso, obtemos os seguintes resultados: 


\section{Itimac \\ T}

Tabela 02- Índices determinados com as janelas abertas.

\begin{tabular}{|c|c|c|}
\hline № da Prancheta & Manhã (lux) & Tarde (lux) \\
\hline 01 & 2000 & 1014 \\
\hline 02 & 2000 & 1060 \\
\hline 03 & 2000 & 978 \\
\hline 04 & 1282 & 774 \\
\hline 05 & 1077 & 721 \\
\hline 06 & 2000 & 1740 \\
\hline 07 & 2000 & 1169 \\
\hline 08 & 1820 & 948 \\
\hline 09 & 1210 & 718 \\
\hline 10 & 1152 & 730 \\
\hline 11 & 1073 & 730 \\
\hline 12 & 2000 & 1212 \\
\hline 13 & 2000 & 1183 \\
\hline 14 & 2000 & 847 \\
\hline 15 & 1154 & 795 \\
\hline 16 & 1045 & 637 \\
\hline 17 & 1005 & 631 \\
\hline 18 & 2000 & 1327 \\
\hline 19 & 2000 & 990 \\
\hline 20 & 1715 & 809 \\
\hline 21 & 1138 & 678 \\
\hline 22 & 1045 & 717 \\
\hline 23 & 974 & 692 \\
\hline 24 & 2000 & 1144 \\
\hline 25 & 2000 & 1071 \\
\hline 26 & 1754 & 880 \\
\hline 27 & 1084 & 754 \\
\hline 28 & 1029 & 709 \\
\hline 29 & 901 & 698 \\
\hline 30 & 2000 & 1633 \\
\hline 31 & 1862 & 1014 \\
\hline 32 & 996 & 821 \\
\hline 33 & 1403 & 737 \\
\hline 34 & 877 & 641 \\
\hline 35 & 837 & 668 \\
\hline
\end{tabular}

Fonte: Autores (2018).

Tabela 03- Índices determinados com as janelas fechadas.

\begin{tabular}{|c|c|c|}
\hline No da Prancheta & Manhã (lux) & Tarde (lux) \\
\hline 01 & 2000 & 400 \\
\hline 02 & 577 & 486 \\
\hline 03 & 548 & 487 \\
\hline 04 & 509 & 482 \\
\hline 05 & 502 & 487 \\
\hline 06 & 625 & 476 \\
\hline 07 & 615 & 499 \\
\hline 08 & 573 & 511 \\
\hline 09 & 516 & 498 \\
\hline 10 & 503 & 500 \\
\hline
\end{tabular}




\begin{tabular}{|c|c|c|}
\hline 11 & 478 & 476 \\
\hline 12 & 2000 & 452 \\
\hline 13 & 595 & 494 \\
\hline 14 & 578 & 503 \\
\hline 15 & 543 & 497 \\
\hline 16 & 504 & 495 \\
\hline 17 & 1055 & 472 \\
\hline 18 & 552 & 407 \\
\hline 19 & 553 & 474 \\
\hline 20 & 552 & 504 \\
\hline 21 & 491 & 491 \\
\hline 22 & 493 & 475 \\
\hline 23 & 481 & 459 \\
\hline 24 & 2000 & 420 \\
\hline 25 & 557 & 469 \\
\hline 26 & 538 & 482 \\
\hline 27 & 519 & 510 \\
\hline 28 & 518 & 508 \\
\hline 29 & 454 & 496 \\
\hline 30 & 697 & 461 \\
\hline 31 & 555 & 473 \\
\hline 32 & 530 & 473 \\
\hline 33 & 521 & 494 \\
\hline 34 & 525 & 461 \\
\hline 35 & 506 & 466 \\
\hline
\end{tabular}

Fonte: Autores (2018).

Tabela 04- Índices determinados no turno da noite.

\begin{tabular}{|c|c|}
\hline No da Prancheta & Noite (lux) \\
\hline 01 & 323 \\
\hline 02 & 423 \\
\hline 03 & 441 \\
\hline 04 & 471 \\
\hline 05 & 499 \\
\hline 06 & 488 \\
\hline 07 & 409 \\
\hline 08 & 457 \\
\hline 09 & 486 \\
\hline 10 & 471 \\
\hline 11 & 499 \\
\hline 12 & 488 \\
\hline 13 & 396 \\
\hline 14 & 454 \\
\hline 15 & 469 \\
\hline 16 & 447 \\
\hline 17 & 490 \\
\hline 18 & 476 \\
\hline 19 & 303 \\
\hline 20 & 397 \\
\hline 21 & 438 \\
\hline 22 & 477 \\
\hline & \\
\hline
\end{tabular}




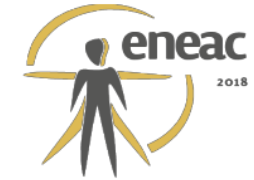

\begin{tabular}{|l|l|}
\hline 23 & 514 \\
\hline 24 & 514 \\
\hline 25 & 308 \\
\hline 26 & 396 \\
\hline 27 & 438 \\
\hline 28 & 437 \\
\hline 29 & 505 \\
\hline 30 & 505 \\
\hline 31 & 415 \\
\hline 32 & 449 \\
\hline 33 & 470 \\
\hline 34 & 497 \\
\hline 35 & 489 \\
\hline
\end{tabular}

Fonte: Autores (2018).

A respeito do questionário aplicado (tabela 01) aos usuários da sala de desenho técnico, em uma população de 90 pessoas, obtivesse uma amostra de 31 pessoas (professores e alunos). Nota-se que, 48,4\% usam a sala de desenho em média de1 à 3 horas por semana; $48,4 \%$ usam a sala de desenho com mais frequência pela tarde; $54,8 \%$ sente desconforto na visão quando estão realizando atividades de alto esforço na sala (desenhando); $29,6 \%$ acredita que o desconforto se dá pela falta de luz do ambiente, principalmente no turno da noite, devido à baixa iluminância.Os principais sintomas citados pelos entrevistados foram desconforto nos olhos por causa da insuficiência da luz, além disso, foi relatado fadiga nos olhos e dores de cabeça. Então, em suma, verificamos a falta de luz na sala e por passar muito tempo desenhando e forçando a vista, tais sintomas se intensificam.

Utilizando a NBR 8995 a fim de uma análise técnica do índice de iluminância no plano de trabalho, tem-se que o valor ideal para o conforto do usuário é um índice de iluminância de no mínimo 750 lux. Em suma, podemos observar que os índices no turno da manhã quando as janelas estão abertas (tabela 02), simulando quando não existia película nos vidros, os valores são maiores que 750 lux, estando assim, de acordo com a norma.

Já no período da tarde, ainda com as janelas abertas (tabela 02), a maioria das pranchetas que estão próximas às janelas apresentam um índice maior que 750 lux, e as que estão próximas a porta, apresentam um valor um pouco menor que o ideal, o que não compromete tanto o visão.

Com as janelas fechadas e com película no vidro, no período da manhã (tabela 03) maioria dos índices são menores que o valor indicado na norma, os únicos que destoam, isto é, são maiores, são as pranchetas que estão realmente ao lado das janelas, devido a radiação solar direta sobre as pranchetas.

No período da tarde (tabela 03), ainda com as janelas fechadas, e no da noite (tabela 04), os índices de todas as pranchetas foram abaixo de 750 lux, o que compromete o conforto visual dos usuários, principalmente, os alunos do curso de Ciência e Tecnologia, pois a disciplina é oferta durante o período da noite.

\section{CONSIDERAÇÕES FINAIS}

Mediante aos argumentos apresentados, conclui-se que todo local, principalmente de estudo e trabalho, deve visar o bem-estar dos seus usuários, pois são locais de longa permanência. Dessa forma, o estudo da ergonomia e a sua aplicação em um ambiente influencia 


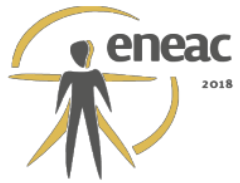

diretamente o indivíduo na sua percepção, produtividade e sensação de bem-estar. Assim, por meio da análise e medições da sala de desenho técnico da UFERSA, Campus Pau dos Ferros, verificamos que a iluminância no plano de trabalho quando não havia a aplicação das películas estava de acordo com o estabelecido na NBR 8995, porém, com as películas os valores dos índices de iluminância é destoante em todos os turnos, uma vez que os índices medidos foram inferiores ao dado na norma, isto é, alunos e professores que utilizam tal local estão sujeitos a fadiga, cansaço nos olhos, estresse e dores de cabeça. Mediante a essa pesquisa, é necessário que ocorra um estudo mais aprofundado para buscar formas de solucionar tal problemática, para que, assim, esse ambiente educacional seja adequado e agradável aos usuários, visto que muitas pessoas utilizam esse local durante um grande período. Proporcionando, com isso, uma atividade segura, saudável, com maior eficiência e produtividade.

\section{REFERÊNCIAS}

ASSOCIOAÇÃO BRASILEIRA DE NORMAS TÉCNICAS. NBR ISSO/CIE 8995-1. Rio de Janeiro: 2013.

BERTOLOTTI, Dimas.lluminação natural em projetos de escolas: uma proposta de metodologia para melhorar a qualidade de iluminação e conservar energia. São Paulo: 2007.

ERGOS SOLUÇÕES EM ERGONOMIA. História da ergonomia. Disponível em: <http://ergos-ergonomia.com.br/historia-da-ergonomia/>. Acesso em: 01 fev. 2018.

IIDA, Itiro. Ergonomia projeto e produção: Projeto e Produção. 2 ed. [S.L.]: Blucher, 2005. $630 \mathrm{p}$.

LAMBERTS, Roberto; DUTRA, Luciano; PEREIRA, Fernando O.R. Eficiência energética na arquitetura. Rio de janeiro: ed.3.

MAXWELL PUC RIO. Ergonomia e usuabilidade. Disponível em: <https://www.maxwell.vrac.pucrio.br/9731/9731_4.pdf>. Acesso em: 08 fev. 2018.

MINISTÉRIO DO TRABALHO. Manual de aplicação da Norma Regulamentadora no17. Brasília: MET, SIT, 2002 . ed.2. Disponível em:<https://d1iOfc51bv4e6i.cloudfront.net/noticias/wp-content/uploads/2014/12/manual- comentadoNR17.pdf >. Acesso em: 04 de set. 2017.

NAKAMURA, Juliana. Como fazer a avaliação pós-ocupação. ed.237. 2013. Disponível em: <http://www.au.pini.com.br/arquitetura-urbanismo/237/como-fazer-a-avaliacao-pos- ocupacao302156-1.aspx >. Acesso em: 08 de set. 2017.

VILLAROUCO, Vilma; ANDRETO, Luiz F. M.. Avaliando desempenho de espaços de trabalho sob o enfoque da ergonomia do ambiente construído. Produção, v. 18, n. 3, p. 523-539, set./dez. 2008. 